\title{
A cancer staging primer: Lung
}

Thomas W. Rice, MD, ${ }^{\mathrm{a}}$ Sudish C. Murthy, MD, PhD, ${ }^{\mathrm{a}}$ David P. Mason, MD, ${ }^{\mathrm{a}}$ and

Eugene H. Blackstone, $\mathrm{MD}^{\mathrm{a}, \mathrm{b}}$

The recently published 7th edition of the American Joint Committee on Cancer (AJCC) Cancer Staging Manual introduces a new, data-driven, and validated lung cancer staging system. ${ }^{1}$ It is based on 67,725 patients with non-small cell lung cancer (NSCLC) assembled by the International Association for the Study of Lung Cancer (IASLC) from 43 institutions. $^{2}$ Cox regression analysis produced more than 180 TNM subsets that were reduced to 8 stage groupings by recursive partitioning and amalgamation.

The new system addresses 3 problem areas: cancer size (Figure 1), satellite nodules (Figure 2), and malignant effusions (Figure 3 ). The resulting redefined $\mathrm{T}$ and $\mathrm{M}$ classifications require a few simple alterations of previous stage grouping. Although derived from analysis of NSCLC data, 7th edition lung cancer staging is also recommended for small cell lung cancer (SCLC) and carcinoid tumors. ${ }^{3,4}$

\section{TNM CLASSIFICATIONS \\ Primary Tumor (T)}

Primary tumor classification (T) is based on the greater of either cancer size (greatest dimension) or local extent (extent of local invasion). With respect to cancer size, $\mathrm{T} 1$ cancers are dichotomized into T1a, which are $\leq 2 \mathrm{~cm}$ and $\mathrm{T} 1 \mathrm{~b}$, which are $>2 \mathrm{~cm}$ to $3 \mathrm{~cm}$ (Figure 1). T2 cancers are dichotomized into T2a, which are $>3 \mathrm{~cm}$ to $5 \mathrm{~cm}$, and T2b, which are $>5 \mathrm{~cm}$ to $7 \mathrm{~cm}$ (Figure 1). T3 cancers are $>7 \mathrm{~cm}$ (Figure 1).

$\mathrm{T}$ is also based on local extent: (1) Invasion of visceral pleura or the main airway $\geq 2 \mathrm{~cm}$ from the carina or atelectasis or (2) obstructive pneumonitis extending to the hilum, but not involving the entire lung (Figure 4), elevates cancers otherwise classified as T1 to T2a. Cancers are T3 by local extent (Figure 5) if there is (1) invasion of parietal pleura or pericardium, chest wall, diaphragm, phrenic nerve, or mediastinal pleura, or main airway $<2 \mathrm{~cm}$ from the carina but without carinal involvement; (2) associated atelectasis or obstructive pneumonia of the entire lung; or (3) satellite nodule(s) (separate tumor nodule[s]) in the same lobe (Figures

\footnotetext{
From the Department of Thoracic and Cardiovascular Surgery, Heart and Vascular Institute, ${ }^{a}$ and the Department of Quantitative Health Sciences, Research Institute, ${ }^{\mathrm{b}}$ Cleveland Clinic, Cleveland, Ohio.

Funded by the Daniel and Karen Lee Endowed Chair in Thoracic Surgery (Dr Rice) and the Kenneth Gee and Paula Shaw, PhD, Chair in Heart Research (Dr Blackstone).

Received for publication Nov 4, 2009; accepted for publication Nov 7, 2009.

Address for reprints: Thomas W. Rice, MD, Cleveland Clinic, Department of Thoracic and Cardiovascular Surgery, 9500 Euclid Ave/Desk J4-1, Cleveland, OH 44195 (E-mail: ricet@ccf.org).

J Thorac Cardiovasc Surg 2010;139:826-9

$0022-5223 / \$ 36.00$

Copyright (c) 2010 by The American Association for Thoracic Surgery doi:10.1016/j.jtcvs.2009.11.010
}

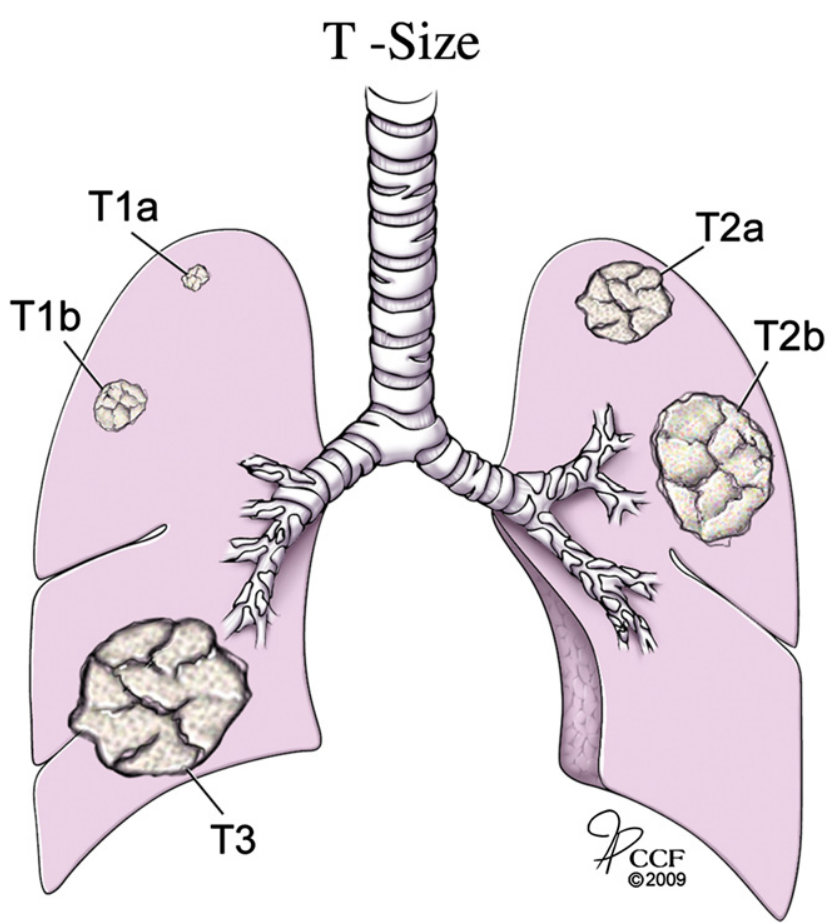

FIGURE 1. $\mathrm{T}$ classification by size (greatest dimension). $\mathrm{T} 1 \mathrm{a}, \leq 2 \mathrm{~cm}$; $\mathrm{T} 1 \mathrm{~b},>2$ to $3 \mathrm{~cm}$; $\mathrm{T} 2 \mathrm{a},>3$ to $5 \mathrm{~cm}$; $2 \mathrm{~b},>5$ to $7 \mathrm{~cm}$; 33 , diam. $>7 \mathrm{~cm}$.

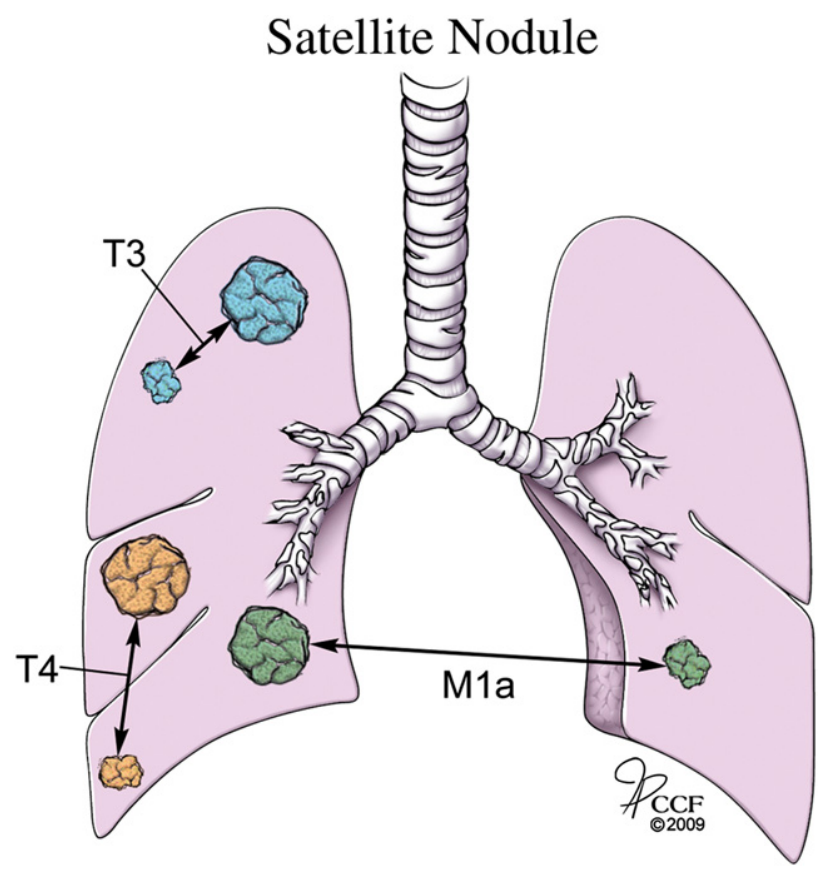

FIGURE 2. Classification of satellite nodules: T3, in same lobe; T4, in a different ipsilateral lobe; and M1a, in contralateral lung. 


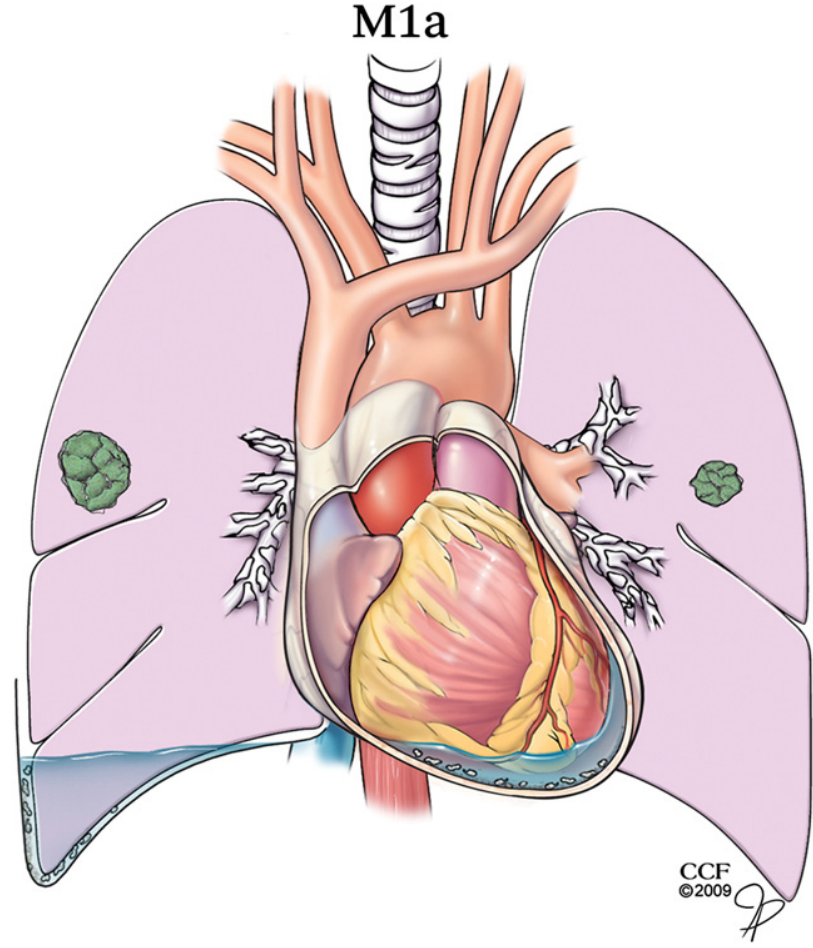

FIGURE 3. M1a cancer. Cancers associated with malignant pleural or pericardial effusion, malignant pleural nodules, or those with satellite nodules in contralateral lung (green).

\section{T2a - Local Extent}

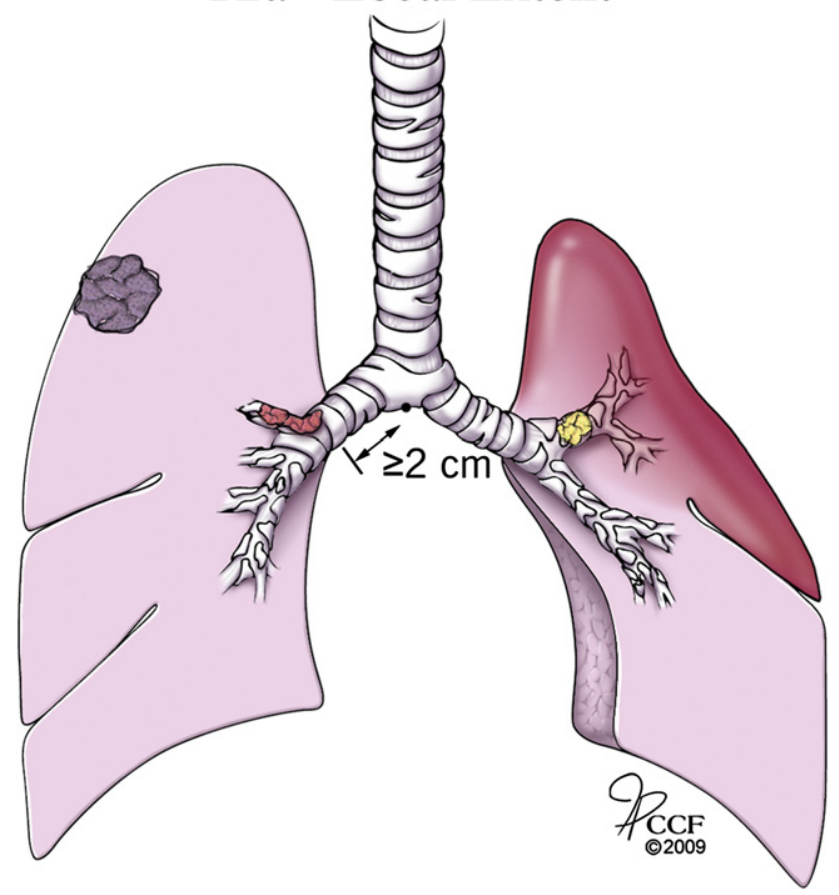

FIGURE 4. T2a cancer by local invasion. Invasion of visceral pleura (purple) or main airway $\geq 2 \mathrm{~cm}$ from the carina ( $r e d)$ or atelectasis or obstructive pneumonia extending to the hilum, but not involving the entire lung (yellow), elevates cancers otherwise classified as $\mathrm{T} 1$ to $\mathrm{T} 2 \mathrm{a}$.

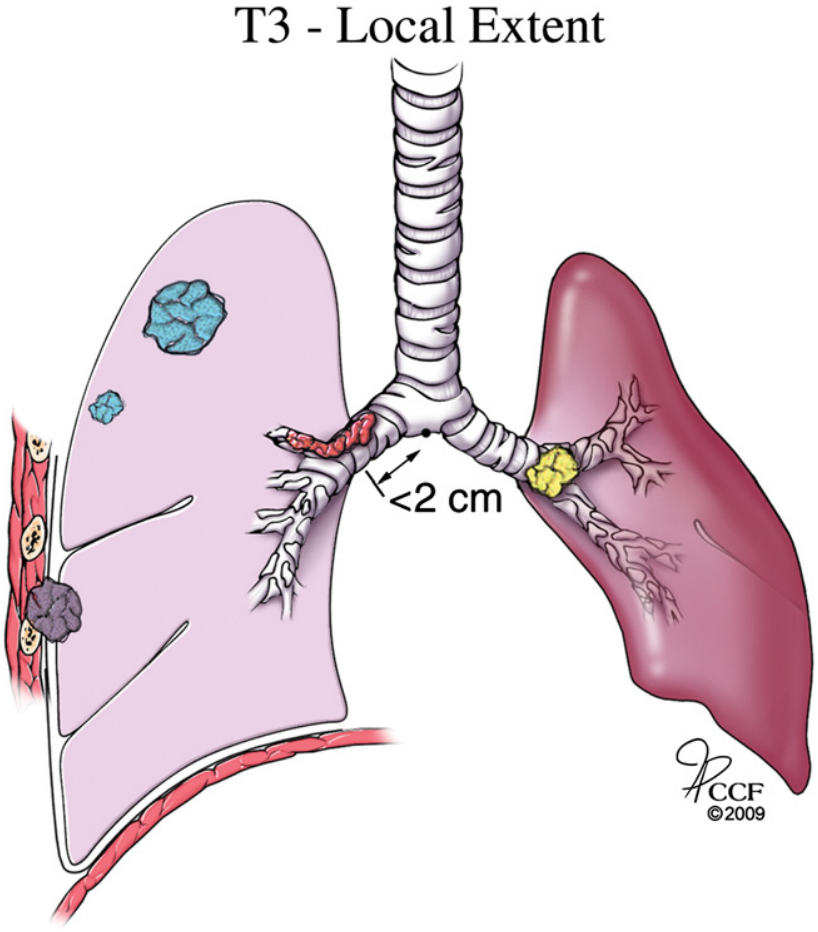

FIGURE 5. T3 cancer by local invasion: (1) invasion of parietal pleura or pericardium, chest wall, diaphragm, phrenic nerve, or mediastinal pleura (purple) or main airway $<2 \mathrm{~cm}$ from the carina (red), without carinal involvement; (2) associated atelectasis or obstructive pneumonia of the entire lung (yellow); and (3) a satellite nodule in the same lobe (blue).

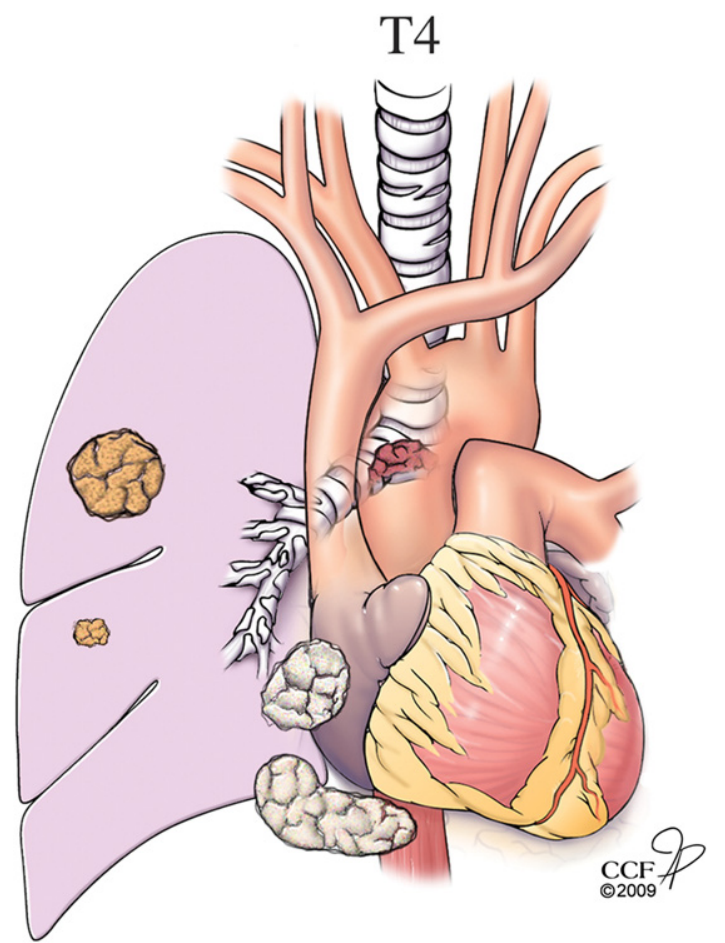

FIGURE 6. T4 cancer: Invasion of the mediastinum, heart, great vessels, trachea, recurrent laryngeal nerve, esophagus, vertebral body, or carina (red), or satellite nodules in a different ipsilateral lobe (orange). 


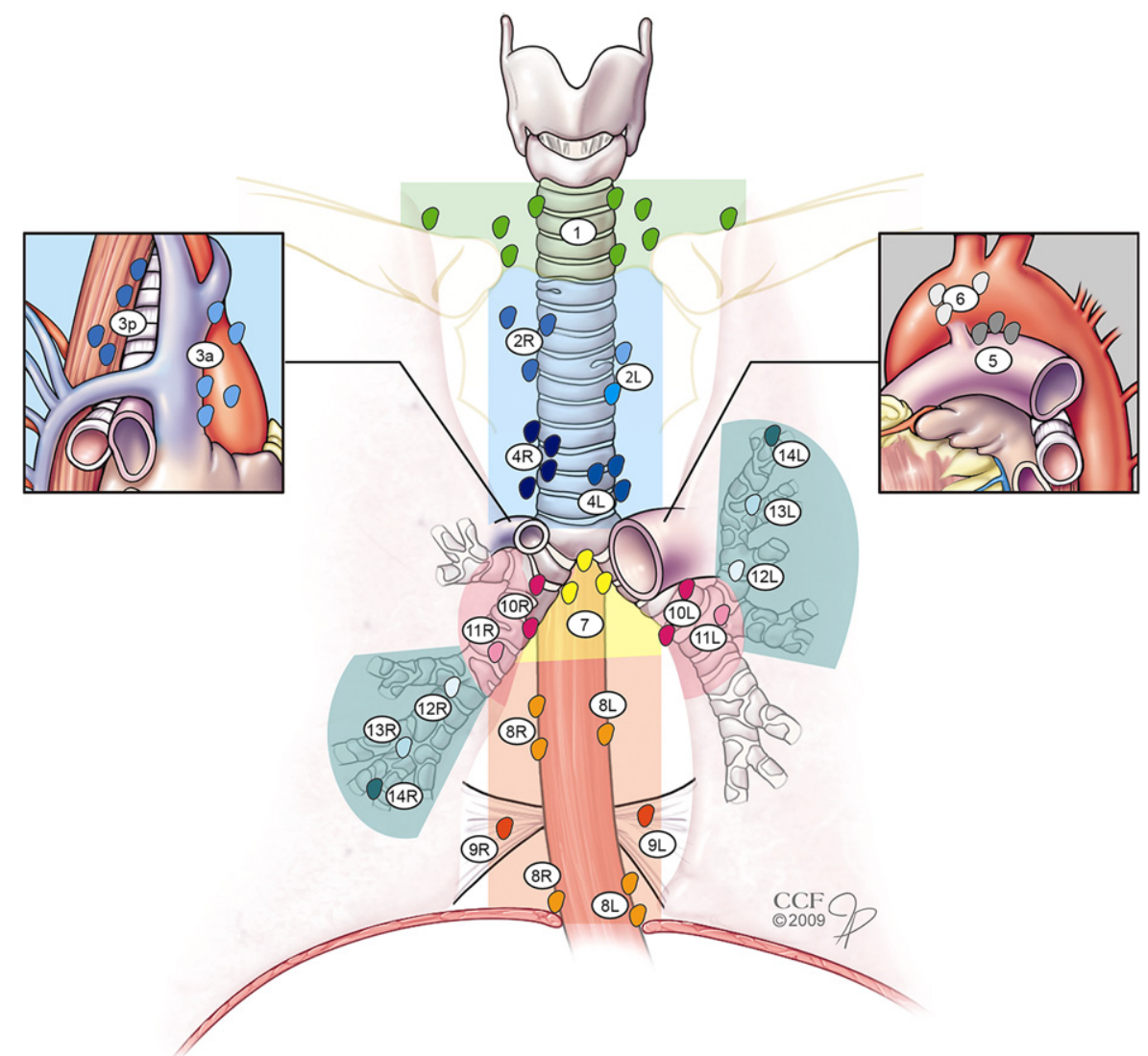

FIGURE 7. Lymph node map: Lymph node zones are supraclavicular (green), upper mediastinal (blue), aortopulmonary (gray), subcarinal (yellow), lower mediastinal (orange), hilar/interlobar (pink), and peripheral (aqua).

TABLE 1. Lymph node zones

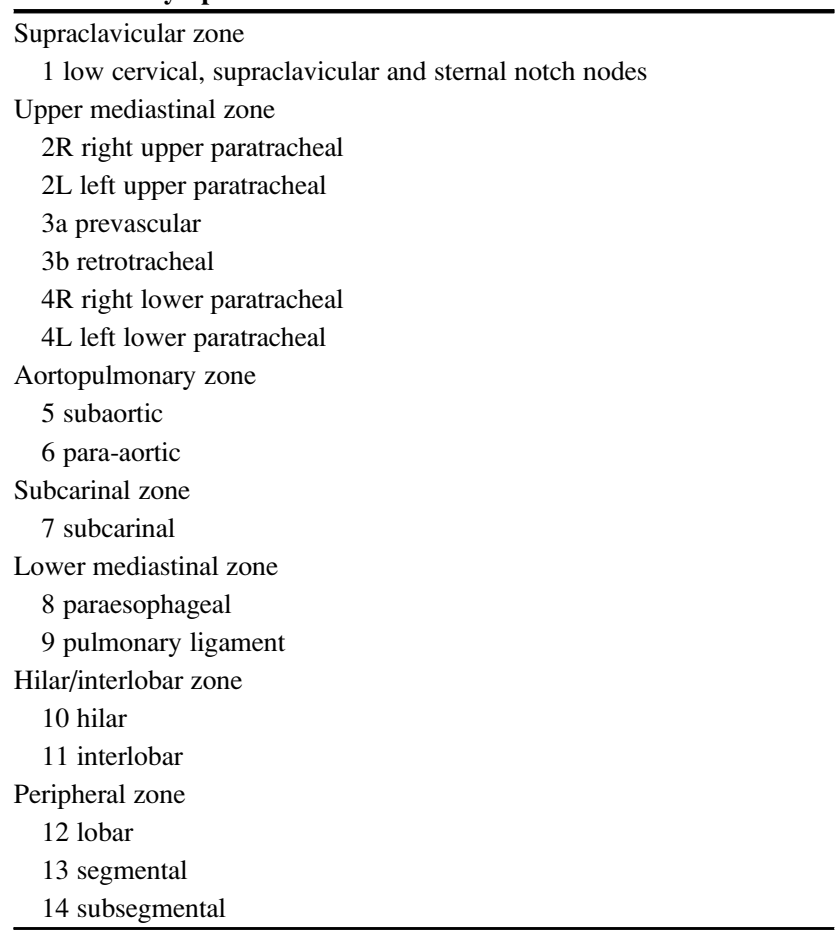

\section{Lung Cancer}

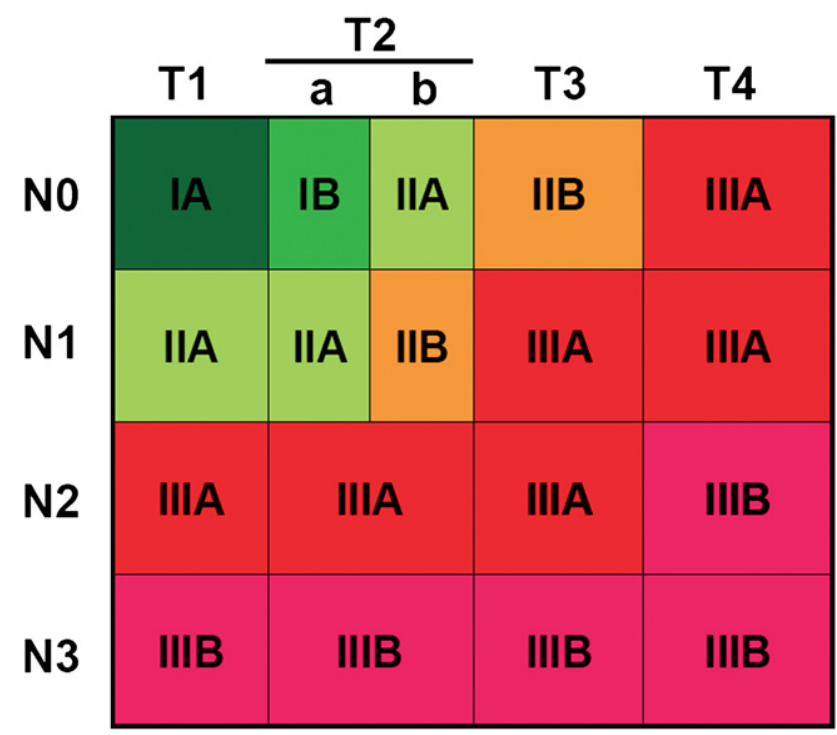

FIGURE 8. Stage groupings for M0 lung cancers. 
2 and 5). T4 cancers are defined only by local extent and include cancers invading the mediastinum, heart, great vessels, trachea, recurrent laryngeal nerve, esophagus, vertebral body, or carina or those with satellite nodules in a different ipsilateral lobe (Figures 2 and 6).

\section{Regional Lymph Node (N)}

Regional lymph node (N) classifications have not changed. However, a unified lymph node map addresses discrepancies among previous nodal mapping proposals and introduces the concept of lymph node zones (Figure 7 and Table 1). ${ }^{1,5}$ Anatomic boundaries of each of the lymph node stations and 7 zones have been painstakingly defined. Regional lymph node classifications are as follows: N0, no regional lymph node metastases; N1, metastases involving hilar/interlobar or peripheral regional lymph node zones; $\mathrm{N} 2$, metastases involving ipsilateral upper mediastinal, subcarinal, lower mediastinal, or aortopulmonary regional lymph node zones; and N3, metastases involving contralateral upper mediastinal, lower mediastinal aortopulmonary, hilar/interlobar or peripheral zones, or involving supraclavicular zone.

\section{Distant Metastasis (M)}

The subclassifications M1a (Figure 3) and M1b have been added. M1a cancers are those with malignant pleural or pericardial effusions, malignant pleural nodules, or satellite nodules in the contralateral lung. All other sites of distant metastases are classified as M1b. The classification $\mathrm{Mx}$ has been eliminated.

\section{Stage Groupings}

Stage 0 is by definition TisN0M0. Stage groupings for M0 lung cancer are shown in Figure 8. The subclassification of T1 does not alter stage group IA, which comprises T1aN0M0 and T1bNOM0 cancers. Stage IB is only T2aN0M0 cancers; this stage group continues to be clinically problematic because it contains tumors both smaller than $4 \mathrm{~cm}$ and $4 \mathrm{~cm}$ or larger, which a recent analysis suggests is the cut point for patients with completely resected cancers who may benefit from adjuvant chemotherapy. ${ }^{6}$
Stage II groups smaller T cancers with N1 regional lymph node metastases and larger $\mathrm{T}$ cancers free of regional lymph node metastases. Stage IIA comprises T1aN1M0, T1bN1M0, T2aN1M0, and T2bN0M0 cancers. Stage IIB comprises T2bN1M0 and T3N0M0 cancers. Stage IIIA comprises T3N1M0, T4N0M0, T4N1M0, and any N2M0 cancer except T4N2M0. Stage IIIB comprises T4N2M0 and any N3M0 cancer. Stage IV is by definition T any N any M1 and is not altered by subclassification of M1.

\section{CONCLUSIONS}

The 7th edition of the AJCC Cancer Staging Manual provides refined lung cancer staging based on analysis of a large international lung cancer database. Primary tumor classification has been modified by addition of size (T1a, T1b, T2a, $\mathrm{T} 2 \mathrm{~b}$, and T3) and satellite nodules (T3 and T4). Subclassification of M1a includes satellite nodules in the contralateral lung, malignant pleural and pericardial effusions, and malignant pleural nodules. Simple changes in stage groupings are required by these TNM classification changes.

\section{References}

1. Edge SB, Byrd DR, Compton CC, Fritz AG, Greene FL, Trotti A III, eds. Lung. In: AJCC Cancer Staging Manual. 7th ed. New York: Springer; 2009:253-70.

2. Goldstraw P, Crowley J, Chansky K, Giroux DJ, Groome PA, Rami-Porta R, et al. The IASLC lung cancer staging project: proposal for the revision of the TNM stage groupings in the forthcoming (seventh) edition of the TNM classification of malignant tumors. $J$ Thorac Oncol. 2007;2:706-14.

3. Vallières E, Shepherd FA, Crowley J, Giroux DJ, Groome PA, Rami-Porta R, et al. The IASLC Lung Cancer Staging Project: proposals regarding the relevance of TNM in the pathologic staging of small cell lung cancer in the forthcoming (seventh) edition of the TNM classification for lung cancer. J Thorac Oncol. 2009;4: 1049-59.

4. Travis WD, Giroux DJ, Chansky K, Crowley J, Asamura H, Brambilla E, et al. The IASLC Lung Cancer Staging Project: proposals for the inclusion of broncho-pulmonary carcinoid tumors in the forthcoming (seventh) edition of the TNM classification for lung cancer. J Thorac Oncol. 2008;3:1213-23.

5. Rusch VW, Asamura H, Watanabe H, Giroux DJ, Rami-Porta R, Goldstraw P. Members of IASLC Staging Committee. The IASLC lung cancer staging project: a proposal for a new international lymph node map in the forthcoming seventh edition of the TNM classification for lung cancer. J Thorac Oncol. 2009;4: 568-77.

6. Strauss GM, Herndon JE II, Maddaus MA, Johnstone DW, Johnson EA Harpole DH, et al. Adjuvant paclitaxel plus carboplatin compared with observation in stage IB non-small-cell lung cancer: CALGB 9633 with the Cancer and Leukemia Group B, Radiation Therapy Oncology Group, and North Central Cancer Treatment Study Groups. J Clin Oncol. 2008;26:5043-51. 